\title{
NHẬN DIỆN VÀ PHÒNG TRÁNH THÔNG TIN XẤU, ĐỘC TRÊN MẠNG XÃ HộI ĐỐI VỚI HỌC SINH, SINH VIÊN TRONG GIAI ĐOẠN HIỆN NAY
}

\author{
LÊ THANH HÒA \\ Khoa Lý luận Chính trị, Trường Đại học Công nghiệp Thành phố Hồ Chi Minh, \\ lethanhhoa@iuh.edu.vn
}

Tóm tắt. Ngày nay, mạng xã hội $(\mathrm{MXH})$ kết nối con người trên toàn thế giới, rút ngắn không gian, thời gian và thúc đầy sự giao lưu hợp tác quốc tế, là kho kiến thức phong phú và đa dạng. Những giá trị tích cực của mạng xã hội mang lại là không hề nhỏ trong thời đại công nghệ số. Tuy nhiên, bên cạnh những hữu ích đó, thực tế cho thấy, mạng xã hội còn tồn tại các mặt tiêu cực như sự lan truyền các thông tin bịa đặt, bóp méo sự thật, xuyên tạc vấn đề, “đổi trắng, thay đen”, xuyên tạc sự thật lịch sử, phủ nhận Chủ nghĩa Mác Lênin, tư tưởng Hồ Chí Minh, chống phá đường lối, chủ trương, chính sách của Đảng, Nhà nước. Những thông tin này được xem là thông tin xấu, độc trên mạng xã hội. Nghiên cứu này nhằm khắc họa bức tranh tổng thể về thực trạng sử dụng mạng xã hội ở Việt Nam trong giai đoạn hiện nay, trong đó có đối tượng là học sinh, sinh viên Việt Nam, qua đó giúp học sinh, sinh viên nhận diện và phòng tránh các thông tin xấu, độc trên mạng xã hội, tránh bị các thế lực xấu lợi dụng.

Từ khóa. Mạng xã hội, Sinh viên, Thông tin xấu, độc

\section{THE IDENTIFICATION AND AVOIDANCE OF BAD AND MALICIOUS INFORMATION ON SOCIAL NETWORKS FOR STUDENTS THESE DAYS}

\begin{abstract}
Nowadays, social networks bridge people around the world. They are not only space-saving but also time-saving, which absolutely promote international cooperation exchanges and give mankind huge and diverse knowledge. There is no room for doubt that social networks bring numerous benefits for our society. Nevertheless, besides the advantages, there are always negative sides which need to be concerned to avoid the misuse of bad objects with fabricated information, distorting a truth and issues, "turning white, replacing black", misrepresent historical facts, denying Marxism-Leninism and Ho Chi Minh's thought Minhism, fighting against orientations and policies of the Party and the State. These kinds of information mentioned above are concerned on bad and malicious information. This study illustrates the overall picture of the current usage of social networks in Viet Nam. The primary object of this study is Vietnamese student in particular. The goal of this study is to help students identify and avoid bad and malicious information from social networks and prevent students from being abused by opposite forces.
\end{abstract}

Keyword: social networks, students, bad and malicious information.

\section{1. ĐẠT VẤN ĐỀ}

Mạng xã hội (social network) là dịch vụ nối kết các thành viên cùng sở thích trên internet lại với nhau, với nhiều mục đích khác nhau không phân biệt không gian và thời gian (còn gọi là mạng xã hội ảo).

Trong những năm gần đây, mạng xã hội $(\mathrm{MXH})$ có bước phát triển mạnh mẽ, tác động lớn đến mọi mặt đời sống kinh tế, xã hội ở hầu hết các quốc gia trên thế giới, trong đó có Việt Nam. Tại Việt Nam, các MXH bắt đầu du nhập từ những năm 2000 dưới hình thức các trang nhật ký điện tử (blog). Theo thống kê của Viện Chiến lược Thông tin và Truyền thông (Bộ Thông tin và Truyền thông), năm 2018, Việt Nam có khoảng $360 \mathrm{MXH}$ của tổ chức, doanh nghiệp trong nước được cấp phép hoạt động, với 55 triệu người sử dụng $\mathrm{MXH}$, chiếm khoảng $57 \%$ dân số, trong đó người sử dụng $\mathrm{MXH}$ qua di động xấp xỉ 50 triệu người. Về thời lượng sử dụng, người Việt Nam vào $\mathrm{MXH}$ hơn 2,5 giờ mỗi ngày. Đối tượng sử dụng mạng internet thường xuyên nhất là nhóm lứa tuổi từ 15-40 tuổi. Nhóm đối tượng này chủ yếu là học sinh, sinh viên và người lao động. Nhìn chung, họ là những người trẻ, có điều kiện tiếp cận với máy tính và mạng internet, nhanh nhạy trong việc tiếp thu những tiến bộ khoa học công nghệ cũng như những trào lưu mới trên thế giới [1]. 
Hiện nay, $\mathrm{MXH}$ đang được sử dụng ngày càng rộng rãi, bởi vì những lợi ích tuyệt vời do xu thế này đang mang lại mà chúng ta không thể phủ nhận. Những lợi ích đó có thể kể đến là: (1) Cập nhật tin tức, kiến thức, xu thế mới nhất của các các vấn đề mà cá nhân yêu thích; (2) Cải thiện chất lượng và tốc độ các cơ quan báo chí đăng tải thông tin và cập nhật những tin tức, đồng thời tiếp nhận nhanh chóng các ý kiến phê bình, góp ý từ người đọc; (3) Dễ dàng kết nối với bạn bè, gia đình, cộng đồng và hòa nhập quốc tế thông qua việc thường xuyên cập nhật thông tin, hình ảnh, trạng thái, cảm xúc,...; (4) Cải thiện, nâng cao kỹ năng sống, kiến thức của khi sử dụng $\mathrm{MXH}$ như tự học về ngoại ngữ, nấu ăn, sửa chữa, giao tiếp, tâm lý, thể thao...; (5) Thuận tiện trong kinh doanh, quảng cáo, tiết kiệm kinh phí, thời gian, sức lao động và thân thiện với môi trường; (6) Là phương tiện để giải trí như nghe nhạc miễn phí, xem phim online, chơi trò chơi điện tử trực tuyến, .... Ngoài ra, riêng đối với sinh viên, những tiện ích mà MXH mang lại còn có nhiều ý nghĩa tích cực khác như nâng cao hiệu quả học tập, giao tiếp và tìm kiếm cơ hội nghề nghiệp,.... Thông qua $\mathrm{MXH}$, sinh viên có thể liên kết hợp tác với nhau thành các nhóm cùng sở thích, cùng sự quan tâm, cùng ý nguyện có thể gặp gỡ, trao đổi trên mạng, làm cơ sở thực hiện những hành động thực tiễn, có ý nghĩa tích cực như: tổ chức các hoạt động từ thiện nhân những ngày Lễ Tết, giúp đỡ trẻ em đường phố, tổ chức những hoạt động sinh hoạt văn hóa lành mạnh; lập ra những trang giúp đỡ nhau học tập tiếng anh hoặc các môn học chuyên ngành.

Bên cạnh những tiện ích nêu trên, MXH còn tồn tại nhiều mặt tiêu cực, mang thông tin xuyên tạc, kích động, bôi nhọ, nói xấu,... Đặc biệt, các thế lực thù địch và tội phạm lợi dụng $\mathrm{MXH}$ làm công cụ đắc lực cho các hoạt động phá hoại tư tưởng, "diễn biến hòa bình" nhằm chống phá Đảng, Nhà nước ta, điều đó đặt ra không ít khó khăn, thách thức cho công tác quản lý thông tin trên MXH.

Những tiện ích mà $\mathrm{MXH}$ mang lại như sử dụng nó trong học tập, giao tiếp và tìm kiếm cơ hội nghề nghiệp, liên kết hợp tác với nhau thành các nhóm người có cùng sở thích, cùng sự quan tâm, cùng ý nguyện có thể gặp gỡ, trao đổi trên mạng rồi tiến tới tổ chức các hoạt động từ thiện nhân những ngày lễ tết, giúp đỡ trẻ đường phố, tổ chức những sinh hoạt văn hóa lành mạnh; nhiều nhóm chia sẻ sở thích du lịch kết hợp việc làm từ thiện ở vùng cao biên giới hẻo lánh... Tuy nhiên, bên cạnh sự năng động, nhiệt huyết của học sinh, sinh viên hiện nay còn có các hạn chế nhất định. Trong đó, hạn chế về phát hiện và ngăn chặn các thông tin xấu, độc trên mạng xã hội hiện nay, trước hạn chế này các đối tượng chống phá Đảng và Nhà nước đã lợi dụng học sinh, sinh viên để thực hiện mục đích của chúng.

Trên các trang MXH trong thời gian qua liên tục xuất hiện hiện tượng một số học sinh, sinh viên đã đăng tải, chia sẻ, bình luận trên MXH, nhất là facebook, những thông tin phiến diện, thiếu chính xác, chưa được kiểm chứng, hoặc thông tin về những vụ việc đang trong quá trình điều tra, chưa có kết luận chính thức... dẫn đến tâm lý hoang mang, phản ứng trái chiều trong dư luận xã hội, tạo cơ hội cho các thế lực thù địch và các đối tượng phản động, cực đoan chính trị tuyên truyền xuyên tạc, chống phá gây mất ổn định chính trị, kinh tế, xã hội. Những thông tin bịa đặt, bóp méo sự thật, xuyên tạc vấn đề, "đổi trắng, thay đen", làm lẫn lộn đúng sai, thật giả hoặc có một phần sự thật nhưng được đưa tin với dụng ý xấu, phân tích và định hướng dư luận bằng luận điệu thù địch. Đó là các dạng thông tin có nội dung không phù hợp về chuẩn mực đạo đức, văn hóa, thuần phong mỹ tục và trái với quy định của pháp luật như: kích động bạo lực, bôi nhọ đời tư, vu khống...; thông tin sai trái, độc hại có tính chất tội phạm tin học như: lừa đảo trên mạng, đánh cắp thông tin, mật khẩu, tán phát vi rút... Những thông tin này được gọi là thông tin xấu, độc trên $\mathrm{MXH}$ hiện nay. Do vậy, nghiên cứu việc nhận diện các thông tin xấu, độc trên MXH đối với học sinh, sinh viên trong giai đoạn hiện này, qua đó, đưa ra các giải pháp phòng và tránh là vấn đề mang tính cấp thiết và có ý nghĩa thực tiễn.

\section{TỔNG QUAN CÁC CÔNG TRÌNH NGHIÊN CỬU CÓ LIÊN QUAN}

Thông tin xấu, độc trên mạng internet đã xuất hiện từ lâu. Tuy nhiên, từ khi cuộc cách mạng công nghệ số bùng nổ với số lượng các $\mathrm{MXH}$ phát triển nhanh, thêm vào đó là số lượng người dung tăng trong đó học sinh, sinh viên là đối tượng sử dụng chiếm tỉ lệ cao, các thế lực phản động đã sử dụng $\mathrm{MXH}$ để thực hiện âm mưu của mình. Trước tình hình đó đã có những nghiên cứu để nhằm đưa những số liệu cụ thể về thực trạng sử dụng $\mathrm{MXH}$, cũng như giúp cho người sử dụng $\mathrm{MXH}$ phòng tránh trước những thông tin không chính xác.

Nghiên cứu của tác giả Nguyễn Thị Lan Hương về "thục trạng sủ dưng mạng xã hội của thanh thiếu niên ơ Việt Nam hiện nay (http://vanhien.vn)" đã phân tích thực trạng về việc sử dụng MXH của thanh thiếu niên, trong đó có học sinh, sinh viên Việt Nam. Tác giả Nguyễn Nhâm, "Phòng chống thông tin xấu độc 
trên mang xã họi (http://lyluanchinhtri.vn)" đã nghiên cứu đưa ra thực trạng sử dụng và nhận diện thông tin xấu, độc trên $\mathrm{MXH}$ để giúp cán bộ, đảng viên có cách nhìn tổng quát và tránh những thông tin trái chiều trên $\mathrm{MXH}$ hiện nay. Cũng nghiên cứu về vấn đề này PGS, TS Trần Nam Chuân - Ths Lê Văn Nam cũng đã đưa ra những giải pháp "ngăn chặn thông tin xấu độc trên $M X H$ (http://cand.com.vn)" nhằm giúp các cá nhân sử dụng chủ động phòng tránh.

\section{THỰC TRẠNG SỬ DỰG MẠG XÃ HỘI Ở VIỆT NAM HIỆN NAY}

\subsection{Các mạng xã hội phổ biến và số người sử dụng}

Đến nay, trên thế giới có nhiều $\mathrm{MXH}$ phổ biến, được nhiều người sử dụng hằng ngày, làm phương tiện giải quyết công việc, giải trí, trao đổi thông tin cá nhân. Theo thống kê của https://socialmedialist.org, tính đến tháng 01/2019, có hơn $250 \mathrm{MXH}$ phổ biến đang có đông số lượng người sử dụng [2]. Bên cạnh đó, theo thống kê của trang web https://www.statista.com về số liệu thống kê về các trang mạng phổ biến nhất trên thế giới được xếp hạng theo số lượng tài khoản đang hoạt động, đến tháng 4/2019, Facebook là ứng dụng dẫn đầu, là trang MXH đầu tiên vượt qua mức 1 tỷ tài khoản đăng ký và hiện đang đạt mức gần 2,320 tỷ người dùng hoạt động hàng tháng [3]. Cụ thể như sau:

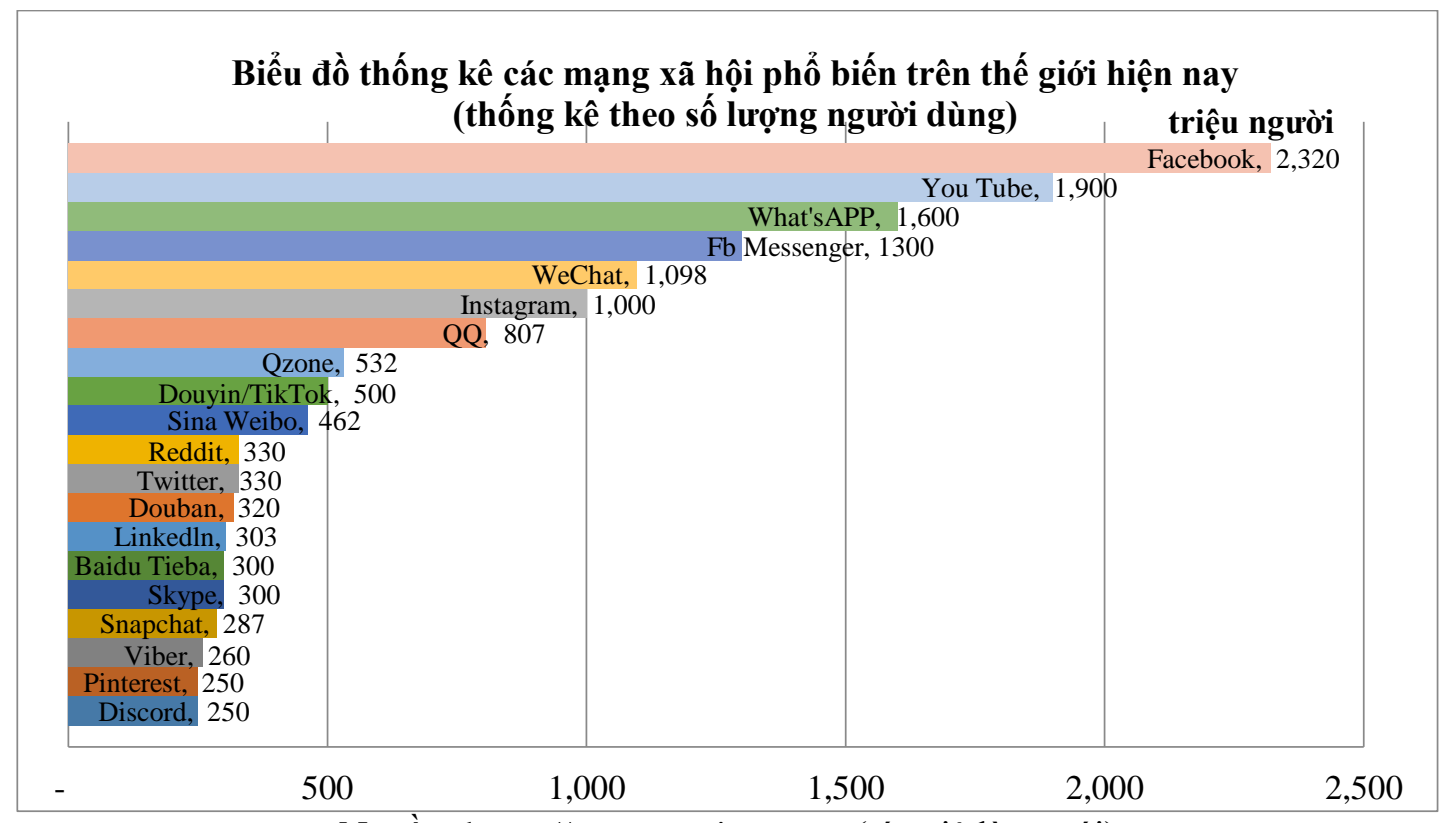

Nguồn: https://www.statista.com (tác giả làm mới)

Về số lượng người dùng MXH trên thế giới, theo thống kê của trang web https://www.dammio.com, tính đến tháng 01/2018, thế giới có hơn 4 tỷ người dùng internet chiếm $53 \%$ dân số thế giới và có hơn 3 tỷ người sử dụng $\mathrm{MXH}$ chiếm tỉ lệ $42 \%$ [4]. Có thể khái quát về số người sử dụng $\mathrm{MXH}$ trên thế giới hiện tại như sau:

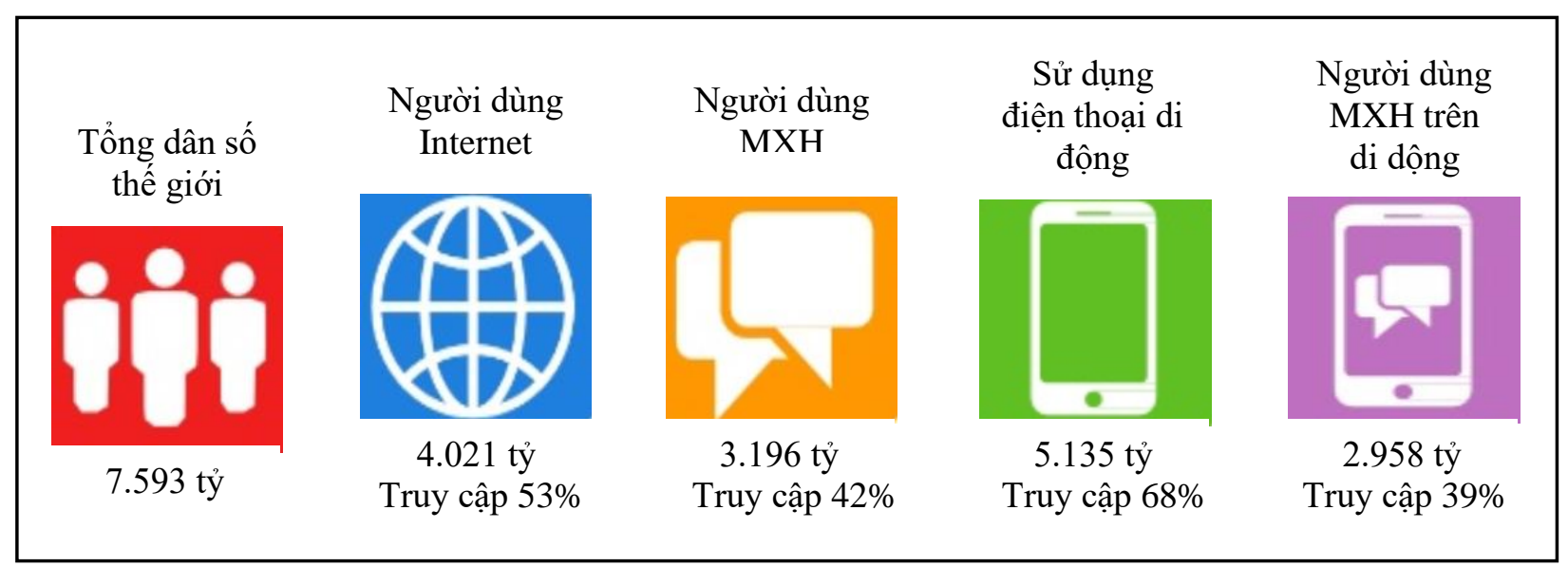

Nguồn: https://www.dammio.com (tác giả làm mới) 
Tại Việt Nam, với sự phát triển mạnh mẽ của công nghệ, MXH đóng góp một phần không nhỏ đưa người Việt Nam hòa nhập với thế giới. Đã có hàng trăm $\mathrm{MXH}$ đang hoạt động sôi nổi, có cả $\mathrm{MXH}$ trong nước và các MXH nước ngoài. Theo số liệu của ComScore - một trong những công ty dẫn đầu thế giới về đo lường và đánh giá hiệu quả các giải pháp marketing trực tuyến, báo cáo về thị trường trực tuyến tại Việt Nam và châu Á đã công bố, Việt Nam hiện là một trong những quốc gia có dân số trực tuyến lớn nhất tại khu vực ASEAN.

Học sinh, sinh viên Việt Nam đang sử dụng các MXH có độ phủ sóng toàn cầu như Facebook, Instagram, Youtube, Twitter, Myspace... và một số mạng nội địa như Zingme, Go.vn, Yume.vn... với nhiều tiện ích đáp ứng được các nhu cầu cá nhân trước những tiện ích MXH mang lại. Trong danh sách các MXH kể trên có lẽ nổi bật nhất vẫn là Facebook, sau đó tới youtube với tính năng hỗ trợ xem và chia sẻ video hiện là trang mạng có lượng người dùng lớn thứ hai ở Việt Nam (56,3\%); đứng thứ ba là Instagram $(24,5 \%)$ chuyên xem và chia sẻ ảnh; Zingme (16,8\%); các mạng Viber, Zalo chiếm tỷ lệ $10 \%$ và các $\mathrm{MXH}$ chiếm tỷ lệ thấp về người dùng như Twitter, Myspace, Gov.vn.

Theo số liệu mới nhất từ Liên Hợp Quốc, tính đến ngày 22/04/2019, dân số Việt Nam là 97.249.676 người. Chiếm $1,27 \%$ dân số thế giới và đang đứng thứ 14 trên thế giới trong bảng xếp hạng dân số các nước và vùng lãnh thổ [5].

Tính đến tháng 10 năm 2018, Việt Nam có 64 triệu người dùng internet chiếm $67 \%$ dân số. Về sử dụng MXH, Việt Nam có đến 55 triệu người dùng đang hoạt động, đạt tỉ lệ $57 \%$ người dùng internet. Tuy nhiên, nếu chỉ xét riêng về MXH Facebook, Việt Nam xếp thứ 7 trong số các quốc gia có người dùng, với 59 triệu người dùng vào tháng 7 năm 2018 [4]. Số liệu người dùng MXH ở Việt Nam được thể hiện cụ thể như sau:

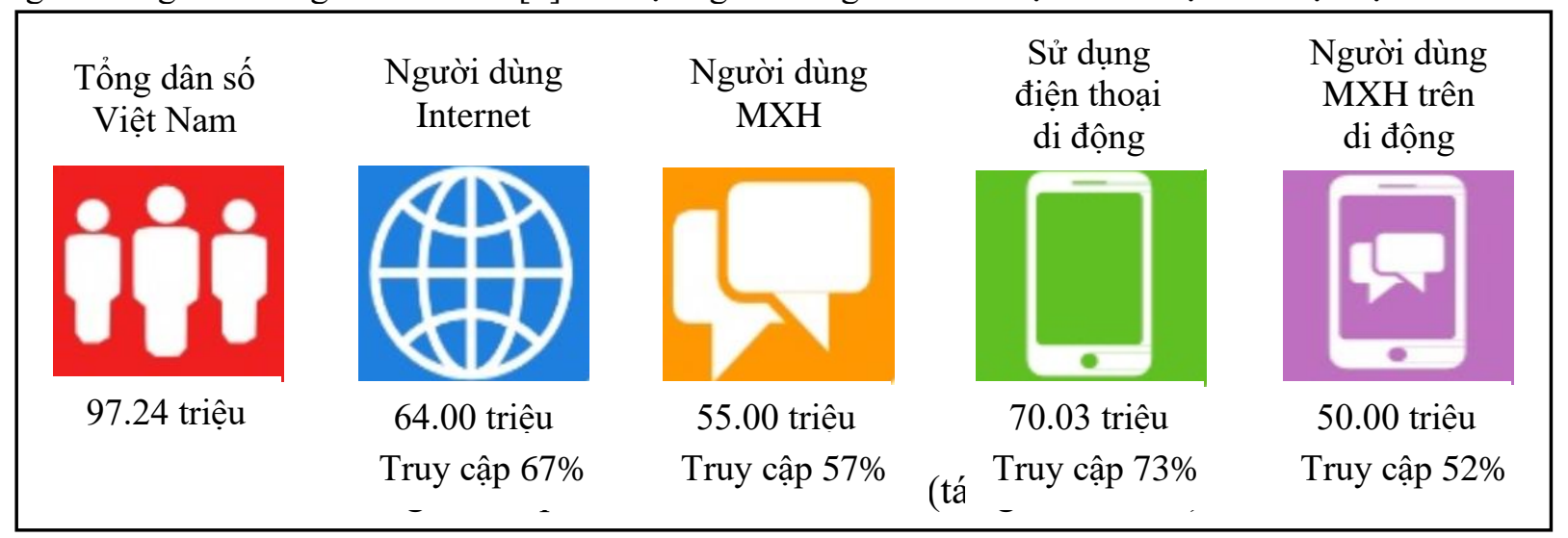

\subsection{Mục đích sử dụng mạng xã hội}

Mục đích của mỗi người khi tham gia MXH hết sức phong phú, đa dạng, song có những mục đích cơ bản như sau: tìm kiếm, cập nhật thông tin xã hội (66,3\%); làm quen với bạn mới, giữ liên lạc với bạn cũ (60\%); liên lạc với gia đình, bạn bè $(59 \%)$. Những nhu cầu này chủ yếu xuất hiện thanh, thiếu niên bởi vì họ đang trong độ tuổi năng động, nhạy bén, sáng tạo, luôn hướng tới cái mới, cái khác biệt và đặc biệt [6].

Phần lớn học sinh, sinh viên sống xa gia đình (đi học, đi làm) nển việc kết nối, thiết lập và duy trì các mối quan hệ (trực tuyến) với người thân, bạn bè sẽ trở thành nhu cầu thiết yếu của mỗi cá nhân. Mục đích chiếm tỷ lệ cao chủ yếu nhằm phục vụ cho nhu cầu giải trí, đây là nhu cầu được các chuyên gia tâm lý nhận định là có chỉ số cao trong giai đoạn phát triển tâm lý ở lứa tuổi này. Bằng cách, tận hưởng những thú vui cuộc sống và khẳng định cái tôi bản thân, đó là chia sẻ thông tin (hình ảnh, video, status) với mọi người $(54,0 \%)$ và để giải trí $(49,5 \%)$. Mục đích tiếp theo, MXH được xem là một công cụ hỗ trợ cho học tập và làm việc, chiếm (44,7\%). Ngoài ra, một bộ phận học sinh, sinh viên còn sử dụng $\mathrm{MXH}$ với nhiều mục đích khác như: mua sắm online $(30,7 \%)$; tìm kiếm việc làm $(21,7 \%)$, hoặc bán hàng online $(13,7 \%) \ldots[6]$.

Như vậy, với nhiều ứng dụng tiện ích khác nhau, các trang MXH đã đáp ứng được gần như đầy đủ các mục đích, nhu cầu của học sinh, sinh viên trong thời đại công nghệ số hiện nay. Việc đăng ký tham gia vào một MXH khá đơn giản và dễ dàng cho hầu hết các đối tượng người dùng như: miễn phí thành viên, có thể truy cập bất cứ khi nào và ở đâu chỉ cần có kết nối internet. 


\section{3 Đối tượng kết nối mạng xã hội}

MXH giới trẻ sử dụng hiện nay không chỉ có các mối quan hệ với gia đình, bạn bè, đồng nghiệp, người quen mà đặc biệt họ còn thiết lập mạng lưới kết nối với những người xa lạ không hề quen biết ngoài đời thực song có cùng sở thích, cùng mối quan tâm, đồng cảm hay chia sẻ với nhau về bất cứ vấn đề gì đó của cuộc sống và xã hội. Đối tượng kết nối của giới trẻ ngày càng đa dạng, tạo nên sự đan xen dày đặc và độ rộng không giới hạn trong một không gian ảo, ở đó không hề bị ngăn cách bởi bất cứ một biên giới nào. Top 3 tỷ lệ cao nhất trong các đối tượng kết nối của học sinh, sinh viên hiện nay là: Những người bạn cùng lớp, cùng quê $(90,2 \%)$; gia đình, họ hàng $(81,3 \%)$; những người bạn trong các nhóm xã hội khác $(48,2 \%)[6]$.

\section{4. Địa điểm và phương tiện sử dụng mạng xã hội}

Học sinh, sinh viên có thể sử dụng MXH ở bất cứ nơi đâu có kết nối internet, đặc biệt khi công nghệ wifi đang ngày càng trở nên phổ biến ở khắp nơi. Tỷ lệ sử dụng $\mathrm{MXH}$ cao thuộc về những không gian mà ở đó sinh viên có quỹ thời gian rảnh rỗi khá nhiều như: Tại nhà chiếm tỷ lệ cao nhất $(95,8 \%)$, trường học $(17,3 \%)$. Hai địa điểm có tỷ lệ truy cập MXH thấp nhất là quán net $(9,5 \%)$ khi mục đích của phần lớn các sinh viên đến đây để chơi game online và thư viện $(2,8 \%)$ [6].

Tần suất sử dụng MXH của học sinh, sinh viên đang có xu hướng ngày càng gia tăng, bởi họ có thể truy cập mọi lúc, mọi nơi nhờ sở hữu các thiết bị công nghệ hiện đại. Học sinh, sinh viên truy cập MXH nhiều nhất thông qua điện thoại di động thông minh chiếm $(85,3 \%)$. Ngoài ra, còn truy cập với các thiết bị công nghệ khác nhu: Máy tính xách tay (24\%), máy tính để bàn (20,5\%), hoặc máy tính bảng $(6,8 \%)$ [6].

\subsection{Ngôn ngữ sử dụng mạng xã hội}

Học sinh, sinh viên sử dụng ngôn từ trên MXH khi viết dòng trạng thái, tán gẫu, bình luận theo những cách riêng của họ đang được xem như một sự thể hiện cá tính hay sự khác biệt với những người khác trong cộng đồng mạng. Hiện nay học sinh, sinh viên thường sử dụng hoàn toàn tiếng Việt để giao tiếp trên $\mathrm{MXH}$ chiếm tỷ lệ cao nhất $(45,7 \%)$. Tuy nhiên, cần lưu ý tiếng Việt dùng để giao tiếp trên $\mathrm{MXH}$ của học sinh, sinh viên hiện nay không thuần nhất như vốn tiếng Việt truyền thống mà họ đã tự "sáng tạo" cho mình một kiểu/loại ngôn ngữ riêng không theo quy chuẩn của tiếng Việt, được gọi nôm na là ngôn ngữ teen [7]. Trong nhiều trường hợp, tiểng Việt được các bạn trẻ thay đổi từ cách viết đến cấu trúc câu, cao hơn là cố tình viết chệch âm, sai lỗi chính tả... Kết hợp tiếng Việt với ngôn ngữ khác (tiếng Anh...) chiếm tỉ lệ $(38,8 \%)$, hoặc những cách viết sáng tạo, viết tắt, sử dụng tiếng lóng hoặc kết hợp nhiều loại ký hiệu khác nhau (29,7\%).

Ví dụ, trên MXH có thể dễ dàng bắt gặp một số xu hướng sử dụng ngôn ngữ của học sinh, sinh viên để diễn đạt lời nói, cảm nghĩ, ý tưởng... của mình như: Diễn đạt theo xu hướng đơn giản hóa như: wá (quá), wen (quen), wên (quên), u (bạn, mày), ni (nay), gato (ghen ăn tức ở)... hay diễn đạt theo xu hướng phức tạp hóa ngôn ngữ: dzui (vui), thoai (thôi), nóa (nó), đóa (đó), dzìa (về), roài (rồi), khoai (khó)... hoặc cố tình viết chệch âm nhằm tạo sự vui vẻ, tinh nghịch trong lời nói như: hem (không), lun (luôn), bùn (buồn), bitk? (biết không?), xiền (tiền)... Một số khác thích sử dụng các từ tiếng Anh viết tắt để diễn đạt như: lol= laugh out loud (cười lớn), tks=thanks (cảm ơn), $\mathrm{pm}=$ private message (nói chuyện riêng), ib = inbox (nhắn tin riêng)...

Nhận định về các kiểu/loại ngôn ngữ riêng mà học sinh, sinh viên đã sáng tạo ra và sử dụng làm công cụ giao tiếp trên $\mathrm{MXH}$ hiện có không ít người phê phán cho rằng đó là thứ ngôn ngữ xa lạ với tiếng phổ thông, thậm chí là làm mất đi sự trong sáng, cái hay, cái đẹp của tiếng Việt, do vậy cần phải có giải pháp khắc phục tình trạng này.

\subsection{Thời gian sử dụng trên mạng xã hội}

Thời gian sử dụng MXH có sự khác biệt nhất định trong sinh viên do phụ thuộc vào nhiều yếu tố chi phối như: quỹ thời gian, không gian, thời điểm, điều kiện kinh tế, tính chất công việc, mục đích lên mạng... của mỗi cá nhân. Thời gian sử dụng $\mathrm{MXH}$ hàng ngày của học sinh, sinh viên thể hiện 3 khoảng thời gian chiếm tỷ lệ cao nhất là: từ 1-3 tiếng (35,7\%); từ $3-5$ tiếng $(25,7 \%)$; trên 5 tiếng chiếm $(22,6 \%)$; trong khi sử dụng ít hơn 1 tiếng chiếm tỷ lệ thấp nhất $(16,0 \%)$. Những số liệu cho thấy học sinh, sinh viên đang dành khá nhiều thời gian cho $\mathrm{MXH}$. Thực tế này đã được nhiều chuyên gia cảnh báo, rằng việc sử dụng không hợp lý quỹ thời gian cho $\mathrm{MXH}$ chính là một trong những nguyên nhân gây nên tình trạng "nghiện" MXH đang ngày càng phổ biến trong một bộ phận giới trẻ [6]. 
Với một loạt các tiện ích của MXH cùng lượng thông tin khổng lồ mà nó có khả năng cung cấp cho người sử dụng, rất nhiều học sinh, sinh viên có thể ngồi lướt mạng cả ngày chỉ để mua sắm online, đọc các status (dòng trạng thái), comment (bình luận), chat (tán gẫu) qua lại với bạn bè hay cả với những người không quen biết... và từ lúc nào họ rơi vào tình trạng "nghiện" $\mathrm{MXH}$, làm lãng phí thời gian, sao nhãng nhiệm vụ học tập, công việc. Đáng báo động hơn là một bộ phận học sinh, sinh viên bị đắm chìm trong cộng đồng mạng nên các đối tượng xấu, các thế lực thù địch đã đưa những thông tin không đúng sự thật hoặc những thông tin chống phá chính quyền từ đó kích động học sinh, sinh viên thực hiện ý đồ của chúng.

\section{NHŨ் THÔNG TIN XẤU, ĐỘC TRÊN MẠNG XÃ HỘI HIỆ NAY}

Theo quy định về mặt pháp luật Việt Nam, việc nhận diện thông tin xấu, độc đã được thể hiện tại khoản 1 Điều 5 Nghị định 72/2013/NĐ-CP và trong Luật An ninh mạng vừa mới được thông qua. Đó là: (a) Chống lại Nhà nước Cộng hòa xã hội chủ nghĩa Việt Nam; gây phương hại đến an ninh quốc gia, trật tự an toàn xã hội; phá hoại khối đại đoàn kết dân tộc; tuyên truyền chiến tranh, khủng bố; gây hận thù, mâu thuẫn giữa các dân tộc, sắc tộc, tôn giáo; (b) Tuyên truyền, kích động bạo lực, dâm ô, đồi trụy, tội ác, tệ nạn xã hội, mê tín dị đoan, phá hoại thuần phong, mỹ tục của dân tộc; (c) Tiết lộ bí mật nhà nước, bí mật quân sự, an ninh, kinh tế, đối ngoại và những bí mật khác do pháp Luật quy định; (d) Đưa thông tin xuyên tạc, vu khống, xúc phạm uy tín của tổ chức, danh dự và nhân phẩm của cá nhân; (đ) Quảng cáo, tuyên truyền, mua bán hàng hóa, dịch vụ bị cấm; truyền bá tác phẩm báo chí, văn học, nghệ thuật, xuất bản phẩm bị cấm; (e) Giả mạo tổ chức, cá nhân và phát tán thông tin giả mạo, thông tin sai sự thật xâm hại đến quyền và lợi ích hợp pháp của tổ chức, cá nhân.

Qua phần thực trạng sử dụng MXH ở Việt Nam đã đề cập tại phần 3, bằng số liệu thứ cấp tác giả đã cụ thể hóa số lượng các $\mathrm{MXH}$ phổ biến và số người sử dụng, xác định rõ mục đích sử dụng, tìm hiểu đối tượng kết nối, địa điểm và phương tiện sử dụng, ngôn ngữ sử dụng và thời gian sử dụng $\mathrm{MXH}$ của học sinh, sinh viên hiện nay. Từ phân tích thực trạng, đã xác định được mục đích và thời gian sử dụng của học sinh, sinh viên đó là tìm kiếm, cập nhật thông tin xã hội; làm quen với bạn mới, giữ liên lạc với bạn cũ; liên lạc với gia đình, bạn bè; tận hưởng những thú vui cuộc sống và khẳng định cái tôi bản thân, đó là chia sẻ thông tin (hình ảnh, video, status) với mọi người và để giải trí. Thời gian sử dụng $\mathrm{MXH}$ hàng ngày của học sinh, sinh viên thể hiện 3 khoảng thời gian chiếm tỷ lệ rất cao nằm trong khoảng từ $1-3$ tiếng chiếm $35,7 \%$; từ $3-5$ tiếng chiếm $25,7 \%$; trên 5 tiếng chiếm $22,6 \%$.

Nắm bắt được thực trạng này, các đối tượng phản động, các thế lực thù địch trong và ngoài nước xác định đối tượng dễ tiếp cận là học sinh, sinh viên để tiến hành các hoạt động phá hoại, tuyên truyền xuyên tạc, chống phá gây mất ổn định chính trị, kinh tế, xã hội. Đưa các thông tin bịa đặt, bóp méo sự thật, xuyên tạc vấn đề, kích động bạo lực, bôi nhọ đời tư, vu khống... Đây là những thông tin xấu, độc trên $\mathrm{MXH}$ cần được nghiên cứu giúp học sinh, sinh viên Việt Nam nhận diện và phòng tránh.

\subsection{Nhận diện}

Trên MXH nước ta thời gian vừa qua liên tục xuất hiện tình trạng một số cá nhân đăng tải, chia sẻ, bình luận trên MXH, nhất là facebook, những thông tin phiến diện, thiếu chính xác, chưa được kiểm chứng, hoặc thông tin về những vụ việc đang trong quá trình điều tra, chưa có kết luận chính thức... dẫn đến tâm lý hoang mang, phản ứng trái chiều trong dư luận xã hội, tạo cơ hội cho các thế lực thù địch và các đối tượng phản động, cực đoan chính trị tuyên truyền xuyên tạc, chống phá gây mất ổn định chính trị, kinh tế, xã hội. Trước thực trạng trên, trước hết cần nhận diện rõ thông tin xấu, độc, từ đó đẩy lùi tác động của nó đối với nhận thức của mỗi người.

Về nội dung và bản chất, có thể nhận diện thông tin xấu, độc tán phát trên internet và MXH là những thông tin bịa đặt, bóp méo sự thật, xuyên tạc vấn đề, “đổi trắng, thay đen”, làm lẫn lộn đúng sai, thật giả hoặc có một phần sự thật nhưng được đưa tin với dụng ý xấu, phân tích và định hướng dư luận bằng luận điệu thù địch. Đó là các dạng thông tin có nội dung không phù hợp về chuẩn mực đạo đức, văn hóa, thuần phong mỹ tục như: kích động bạo lực, bôi nhọ đời tư, vu khống...; thông tin sai trái, độc hại có tính chất tội phạm tin học như: lừa đảo trên mạng, đánh cắp thông tin, mật khẩu, tán phát vi rút...

Về thủ đoạn tán phát thông tin xấu, độc, các thế lực thù địch, phản động, cơ hội chính trị đang sử dụng các phương thức, thủ đoạn mới, tinh vi, xảo quyệt. Chúng lợi dụng các trang mạng lớn trên thế giới như Google, Facebook, kênh Youtube làm công cụ, sử dụng và nhân rộng mạng lưới cộng tác viên rộng khắp để xuyên 
tạc, chống phá ta; tận dụng tối đa những ý kiến, đánh giá, nhận xét của các cá nhân, tổ chức có uy tín, có tầm ảnh hưởng trong và ngoài nước, tạo dựng các trang web, các tài khoản cá nhân trên mạng nói chung, trên Facebook nói riêng để "chia sẻ”, phát tán thông tin xuyên tạc, bịa đặt chống phá.

Những thủ đoạn tán phát thông tin xấu, độc bao gồm: Các đối tượng sử dụng điện thoại thông minh, máy tính bảng... để quay phim, chụp ảnh, truyền tải video, hình ảnh livestream trực tiếp từ thực địa phát tán trên MXH một cách nhanh chóng và tác động trực tiếp tới những người tham gia $\mathrm{MXH}$, tạo hiệu ứng lan truyền rộng khắp; giả mạo các hình ảnh, video hoặc sử dụng các thông tin cũ có hiệu ứng kích động cao đối với cộng đồng mạng để xuyên tạc, lôi kéo người dân; giả mạo lực lượng chức năng (quân đội, công an) trà trộn vào lực lượng tham gia biểu tình hoặc có những hành vi phản cảm để quay phim, chụp ảnh phát tán lên mạng internet, $\mathrm{MXH}$. Tạo hiệu ứng đám đông trên không gian mạng bằng cách huy động một số lượng lớn các tài khoản $\mathrm{MXH}$ (đa số là các tài khoản ảo) gắn các biểu ngữ phản đối Đảng, Nhà nước để tạo ra hiệu ứng đám đông, từ đó người dùng $\mathrm{MXH}$ thường xuyên nhìn thấy các biểu ngữ phản đối hoặc những người không có lập trường tư tưởng vững vàng sẽ bị tác động thay đổi tư tưởng theo chiều hướng tiêu cực; giả mạo tài khoản, xây dựng hàng loạt các mạng lưới tài khoản, trong đó có một số tài khoản chính thường xuyên đăng tải bài viết, thông tin xuyên tạc về một số nội dung, lĩnh vực nhất định và sử dụng hàng trăm tài khoản vệ tinh (thực chất là tài khoản ảo, có chung một chủ tài khoản) thực hiện nhiệm vụ chia sẻ trong các nhóm diễn đàn phản động hoặc các trang $\mathrm{MXH}$ có lượng thành viên lớn; Đặc biệt, có nhiều tài khoản được thế lực thù địch mạo danh các nhân vật nổi tiếng, có ảnh hưởng đến cộng đồng để phát huy tối đa khả năng lan truyền thông tin gây hoang mang dư luận trong quần chúng nhân dân, kích động người dân tụ tập biểu tình ngoài thực địa và có hành vi vi phạm pháp luật.

Xu hướng tán phát thông tin xấu, độc trên MXH trong thời gian tới sẽ tập trung chủ yếu vào những vấn đề sau: Dựa trên những vấn đề phức tạp, mới nảy sinh, những yêu cầu phát triển của đất nước, nhất là sự gia tăng nhanh chóng số lượng người sử dụng $\mathrm{MXH}$, các diễn biến theo chiều hướng phức tạp trong khu vực và Biển Đông; lợi dụng những biểu hiện mới xuất hiện trên thế giới, như khuynh hướng chống toàn cầu hóa để xuyên tạc, cản trở đường lối đối ngoại của Đảng và Nhà nước ta, kích động, cổ vũ cho chủ nghĩa dân tộc hẹp hòi, cực đoan phát triển. Cổ vũ xây dựng "Xã hội dân sự" ở Việt Nam, lợi dụng vấn đề dân chủ, nhân quyền và hàng loạt vấn đề cốt lõi trong xây dựng Đảng, xây dựng hệ thống chính trị, nhất là việc triển khai thực hiện Nghị quyết Trung ương 4 (khóa XII) và các nghị quyết mới của Trung ương để chống phá.

Mục đích phát tán thông tin xấu, độc nhằm hướng nội dung tác động đến các đối tượng như: công nhân trong vấn đề cho phép hình thành tổ chức công đoàn độc lập; nông dân trong việc triển khai chủ trương tích tụ ruộng đất, phát triển nông nghiệp theo hướng công nghiệp hóa nông nghiệp, nông thôn, xây dựng nông thôn mới, cánh đồng mẫu lớn; văn nghệ sĩ, trí thức trong việc hình thành các hội nhóm đối lập núp dưới danh nghĩa phản biện xã hội... Các đổi tượng chống phá còn tập trung lựa chọn những nhân tố "điển hình", "sám hối", "trở cờ", suy thoái về tư tưởng chính trị, đạo đức, lối sống, "tự diễn biến", "tự chuyển hóa" trong nội bộ làm "ngọn cờ" trên địa bàn để tập hợp lực lượng chống đối từ bên trong. Bên cạnh đó, đưa những thông tin sai trái, bịa đặt, bóp méo, xuyên tạc sự thật, lẫn lộn đúng sai, thật giả, hoặc có một phần sự thật nhưng được đưa tin với dụng ý xấu, thông tin chưa được kiểm chứng gây ảnh hưởng đến cá nhân, tổ chức; thông tin có những ngôn từ thô tục, nội dung phản cảm, soi mói, xúc phạm danh dự, nhân phẩm cá nhân, vi phạm chuẩn mực đạo đức, văn hóa, thuần phong mỹ tục; kích động đồi trụy, bạo lực... được coi là thông tin xấu, độc.

Hình thức phát tán thông tin xấu, độc trên $\mathrm{MXH}$ rất đa dạng, tinh vi. Các đối tượng xấu thường núp dưới vỏ bọc các tổ chức "xã hội dân sự", "diễn đàn dân chủ"... để tuyên truyền, xuyên tạc đường lối, quan điểm, cương lĩnh, nền tảng tư tưởng của Đảng, nhất là những vấn đề "dân chủ", "nhân quyền", "dân tộc", "tôn giáo”. Lợi dụng một số cá nhân thoái hóa, biến chất về phẩm chất chính trị, đạo đức, lối sống, hoặc có tham vọng chính trị cao, thành lập các hội, fanpage... làm cơ quan ngôn luận, địa chỉ hoạt động cho tổ chức "dân chủ" trên mạng. Lợi dụng MXH phát tán rộng rãi các tài liệu, văn hóa phẩm có nội dung xấu, độc, phản động, từ đó kích động hình thành các hoạt động như tuần hành, biểu tình, rải truyền đơn, tụ tập kêu gọi chống đối cán bộ địa phương, gây mất ổn định an ninh chính trị, trật tự an toàn xã hội, chống phá chính quyền, chia rẽ khối đoàn kết giữa Đảng và Nhân dân.

Các đối tượng tung tin thường sử dụng các website, dịch vụ thư điện tử (e-mail) và các trang MXH (Facebook), Zalo (các dịch vụ chat, nhắn tin, hội thoại), truyền thoại (VoIP), diễn đàn (forum), Twitter, 
Youtube, MySpace... để đưa thông tin xấu độc. Cách thức tiến hành của chúng thường là tổng hợp tin tức từ các báo chính thống để tạo ra sự khách quan, sau đó cài dần các thông tin xấu, độc, theo tỷ lệ tăng dần cả về số lượng và mức độ bịa đặt, bóp méo sự thật, luận điệu sai trái.

Một thủ đoạn khác mà các đối tượng thù địch sử dụng là thiết lập trang mạng mạo danh tổ chức hoặc cá nhân, đưa ra những thông tin không đúng sự thật nhằm tạo ra hình ảnh méo mó về đất nước và con người Việt Nam, về các tổ chức và cá nhân. Các đối tượng xấu cũng lợi dụng những yếu kém trong công tác quản lý, công tác cán bộ, những sai phạm của một số tổ chức, cá nhân để nói xấu, bôi nhọ, vu cáo, bịa đặt đối với Đảng, Nhà nước, gây tác động tiêu cực đến dư luận xã hội, làm giảm sút lòng tin của nhân dân đối với Đảng, Nhà nước và chế độ.

Từ nội dung, bản chất, thủ đoạn, mục đích và hình thức phát tán thông tin trên $\mathrm{MXH}$ hiện nay, ở nước ta đang đang có những thông tin được coi là xấu, độc cụ thể như sau: (1) Thông tin chống phá nền tảng tư tưởng của Đảng và cách mạng Việt Nam, phủ định chủ nghĩa Mác - Lênin và tư tưởng Hồ Chí Minh; (2) Xuyên tạc đường lối xây dựng $\mathrm{CNXH}$, đường lối bảo vệ Tổ quốc và đường lối đối ngoại của Đảng ta, phủ nhận những thành tựu của sự nghiệp đổi mới; (3) Xuyên tạc lịch sử dân tộc, nhất là lịch sử các cuộc kháng chiến, các cuộc chiến tranh bảo vệ Tổ quốc của nhân dân ta; (4) Xuyên tạc thân thế và sự nghiệp của Chủ tịch Hồ Chí Minh, phủ nhận công lao to lớn của Người đối với sự nghiệp cách mạng của Đảng và dân tộc; vu cáo, bôi nhọ, giả mạo các đồng chí lãnh đạo cao cấp của Đảng, Nhà nước, tướng lĩnh trong quân đội; (5) Kích động xu hướng ly khai, phá hoại sự thống nhất quốc gia, dân tộc, gây chia rẽ đoàn kết nội bộ, thúc đẩy "tự diễn biến", "tự chuyển hóa" trong nội bộ; (6) Truyền bá lối sống ích kỷ vụ lợi, xa hoa, trụy lạc, bạo lực và thù hận (hate speech) đối với cá nhân và tổ chức; (7) Phá hoại bản sắc văn hóa dân tộc, tuyên truyền, áp đặt các giá trị văn hóa và lối sống phương Tây; (8) Lừa đảo trên mạng, đánh cắp thông tin, mật khẩu, phát tán virus...

\subsection{Các biểu hiện cụ thể của thông tin xấu, độc xuất hiện thời gian gần đây}

Thứ nhất, tổ chức lưu vong ở nước ngoài lôi kéo thực hiện chống phá Đảng và Nhà nước

Đầu tiên, tổ chức khủng bổ "Chính phủ quốc gia Việt Nam lâm thời" tiền thân là tổ chức "Tân Dân Chủ", trụ sở đặt tại 2807 Anaheim, CA 92814, Mỹ với mục đích lật đổ Nhà nước CHXHCN Việt Nam, khôi phục chế độ Việt Nam cộng hòa. Từ tháng 01/2018, Bộ Công an đã xác định tổ chức "Chính phủ quốc gia Việt Nam lâm thời” là tổ chức khủng bố. Cầm đầu là Đào Minh Quân (nguyên Trung úy Ngụy), sinh năm 1952, quê quán tại Kỳ Hương, Tam Kỳ, Quảng Nam. Hiện tại, Đào Minh Quân đang sống tại bang California, Mỹ. Ngày 06/06/2009, Đào Minh Quân công bố bản "Hiến ước lâm thời" thể hiện cương lĩnh và điều lệ hoạt động của tổ chức, với mục đích nhằm xóa bỏ vai trò lãnh đạo của Đảng Cộng sản Việt Nam, Nhà nước CHXHCN Việt Nam bẳng bạo động vũ trang với khẩu hiệu hành động "lấy lại đất tổ, không làm khổ dân".

Bằng phương thức, thủ đoạn lợi dụng internet, chúng tạo lập, duy trì các trang web, blog, địa chỉ email như "chinhphuquocgia.com", laylaidatto@gmail.com", "cuutuchinhtri.org”... để tuyên truyền, lôi kéo, phát triển lực lượng, chỉ đạo thực hiện các hoạt động chống phá Nhà nước Việt Nam dưới nhiều hình thức như hoạt động khủng bố, phá hoại tư tưởng, rải truyền đơn kích động biểu tình, phá hoại nhân dịp các ngày lễ, Tết của đất nước.

Bên cạnh đó, tổ chức "Triều đại Việt" (hay "Triều đại Việt Nguyễn") có trụ sở chính tại Canada, do đối tượng Ngô Văn Hoàng Hùng cùng với các đối tượng Trần Thanh Đình, Ngô Cường, Trần Công Tuấn, Huỳnh Thanh Hoàng, Lê Thái Hoàng và Nguyễn Thanh Long nguyên là thành viên cốt cán của tổ chức khủng bố "Chính phủ quốc gia Việt Nam lâm thời", Các đối tượng chủ trương hoạt động bạo động vũ trang, lật đổ Đảng và Nhà nước ta với phương châm "đốt sạch", "giết sạch", "phá sạch", "cướp sạch" và lấy cờ ngũ sắc làm quốc kỳ. Thực hiện âm mưu chống phá Việt Nam, Ngô Văn Hoàng Hùng cùng các đối tượng lên MXH Facebook, Youtube đăng tải gần 200 video, clip dưới hình thức livestream với nội dung xuyên tạc lịch sử, xuyên tạc Nhà nước Việt Nam, kêu gọi người dân đứng lên đấu tranh bạo động, lật đổ chế độ, ủng hộ "Triều Đại Việt" về lãnh đạo đất nước.

Thứ hai, lợi dụng vấn đề ô nhiễm môi trường biển tại các tỉnh miền Trung năm 2016

Các đối tượng phản động đã đăng tải các video, hình ảnh không đúng sự thật lên $\mathrm{MXH}$, dưới sự chỉ đạo của các tổ chức phản động, đối tượng cực đoan nhằm xuyên tạc, bôi nhọ lãnh đạo Đảng, Nhà nước Việt Nam mà còn tích cực khoét sâu và thổi phồng các vấn đề nóng như sự cố môi trường, lũ lụt trên địa bàn Hà Tĩnh, Nghệ An, Quảng Bình để kích động nhân dân, làm giải sự uy tín của Đảng, Nhà nước, hòng làm suy giảm 
khối đại đoàn kết toàn dân, bóp méo sự thật, bàn về vấn đề nhân quyền ở nước ta. Sau khi cơ quan chức năng khởi tố vụ án hình sự để xử lý các đối tượng cầm đầu thì xuất hiện một số trang $\mathrm{MXH}$ ở nước ngoài đã đăng tin Việt Nam vi phạm quyền tự do tôn giáo, vi phạm tự do dân quyền và còn cho rằng Việt Nam đàn áp tôn giáo.

Trường hợp điển hình: Những kẻ có mưu đồ xấu đã kích động, tụ tập giáo dân ở các tỉnh Nghệ An, Hà Tĩnh tuần hành, gây rối trật tự công cộng khiến dư luận bất bình. Cụ thể, ngày 10/2/2017, linh mục Nguyễn Đình Thục - Quản xứ Song Ngọc (xã Quỳnh Ngọc, huyện Quỳnh Lưu, Nghệ An) soạn thảo "thư ngỏ" kêu gọi các linh mục và cộng đoàn các Giáo xứ Hiệp Thông, cầu nguyện cho giáo dân Giáo xứ Song Ngọc đi gửi đơn khởi kiện Công ty TNHH Hưng Nghiệp Formosa tại Tòa án Nhân dân Thị xã Kỳ Anh (tỉnh Hà Tĩnh) vào ngày 14/2. Trong quá trình tập kết vào bãi đất trống, linh mục Thục đã chỉ đạo dừng xe ô tô 7 chỗ ngồi ngay giữa quốc lộ $1 \mathrm{~A}$. Khi xe dừng, các đối tượng ngồi trong xe không chịu mở cửa buộc lực lượng CSGT phải cẩu xe và người ngồi trên xe để giải phóng ách tắc giao thông. Cũng trong năm 2017, Linh mục Đặng Hữu Nam xuyên tạc lịch sử, kích động trẻ em ra đường. Tối 30/4, trong bài rao giảng tại nhà thờ, Đặng Hữu Nam đã có những lời lẽ kích động, bóp méo sự thật về ngày 30/4/1975, chia rẽ mối đoàn kết dân tộc. Một vụ việc khác, kích động 2.000 người bao vây trụ sở UBND huyện. Khoảng 8 h ngày 3/4/2017, có khoảng 2.000 người dân (chủ yếu là Giáo dân ở xã Thạch Bằng và xã Thạch Kim, huyện Lộc Hà, Hà Tĩnh) do Bạch Hồng Quyền cầm đầu, kích động mang theo băng rôn, khẩu hiệu kéo đến UBND huyện Lộc Hà để khiếu nại, đòi bồi thường thiệt hại sự cố môi trường biển [8].

Thứ ba, bóp méo, xuyên tạc các vụ án hình sự

Khởi tố và xử lý kịp thời, đúng người, đúng tội các vụ án hình sự là trách nhiệm của cơ quan pháp luật. Điều này có ý nghĩa rất quan trọng đối với công tác đấu tranh phòng, chống tội phạm, đảm bảo an ninh trật tự xã hội, mang lại sự bình yên cho nhân dân ở bất kỳ quốc gia nào. Tuy nhiên, có những phần tử co hội, bất mãn chính trị đã lợi dụng những vụ án mà trắng đen đã rõ mười mươi, đề thực hiện những thủ đoạn đơm đặt, dựng chuyện, cố tình làm sai lệch bản chất sự việc. Mục đích là nhằm hạ uy tín của các cơ quan công quyền, cơ quan thực thi pháp luật, gây nhiễu thông tin, lèo lái dư luận ngả theo quan điểm sai trái, bất mãn.

Trường hợp điển hình: Ngày 22/6/2017, cơ quan cảnh sát điều tra Công an Thành phố Yên Bái đã bắt ông Lê Duy Phong (32 tuổi, ở Hải Ninh, Tĩnh Gia, Thanh Hóa) Trưởng ban Bạn đọc Báo điện tử Giáo dục Việt Nam khi ông này được cho là có hành vi lợi dụng hoạt động báo chí để chiếm đoạt tài sản của một doanh nghiệp tại phường Nguyễn Thái Học, TP. Yên Bái. Bước đầu phía Công an TP Yên Bái thông tin, bằng thủ đoạn như trên, ông Lê Duy Phong đã chiếm đoạt của một số doanh nghiệp trên địa bàn tỉnh Yên Bái số tiền 250 triệu đồng. Ngày 20/4/2018, TAND TP Yển Bái (tỉnh Yên Bái) đã mở phiên tòa xét xử sơ thẩm bị cáo Lê Duy Phong bị truy tố về tội "Cưỡng đoạt tài sản". Sau 1 ngày xét xử HĐXX đã tuyên phạt bị cáo Lê Duy Phong 3 năm tù giam, thời hạn tù tính từ ngày 22/6/2017 [9].

Sau khi nhà báo Lê Duy Phong bị cơ quan chức năng truy tố về tội cưỡng đoạt tài sản, trên một số trang MXH các phần tử phản động đã đăng tải các thông tin, hình ảnh bóp méo, xuyên tạc vụ việc trên và cho Việt Nam vi phạm tự do báo chí, chính quyền Việt Nam gài bẫy để đưa các nhà báo chống tham nhũng vào các vòng lao lý.

Thứ tư, chống người thi hành công vụ, quay chụp video và hình ảnh để đưa lên $\mathrm{MXH}$

Đặc biệt hiện nay có một số đối tượng dàn dựng để quay phim, chụp hình các cán bộ thi hành công vụ để đưa lên $\mathrm{MXH}$. Bằng biện pháp kẻ tung, người hứng để dàn dựng quay phim, chụp ảnh sau đó đưa lên $\mathrm{MXH}$ bằng lời lẽ thách thức, bóp méo xuyên tạc các cơ quan chức năng đang thực hiện công vụ. Những vấn đề mà chúng đưa dàn dựng trong các video đó là tố cáo tham nhũng, cán bộ thi hành công vụ thực hiện trái với quy định của pháp luật. Những video, hình ảnh sau khi được đưa lên $\mathrm{MXH}$ gây ra nhiều thông tin trái chiều trong thời gian dài.

Trường hợp điển hình: Sáng ngày 09/4/2019, Cơ quan Cảnh sát điều tra - Công an thành phố Yên Bái (tỉnh Yên Bái) đã thi hành Lệnh bắt bị can để tạm giam thời hạn 2 tháng đối với Trần Đình Sang (SN 1980, ở tổ 7, phường Minh Tân, thành phố Yên Bái) về tội “Chống người thi hành công vụ". Lệnh bắt bị can để tạm giam đã được Viện KSND cùng cấp phê chuẩn.

Theo điều tra ban đầu, tối 23/3/2019, tổ tuần tra của Phòng Cảnh sát cơ động - Công an tỉnh Yên Bái làm nhiệm vụ tuần tra lưu động trên các tuyến đường tại thành phố Yên Bái thì phát hiện một nam thanh niên điều khiển xe máy chở theo 2 người ngồi phía sau, cả ba không đội mũ bảo hiểm, chiếc xe không có gương 
chiếu hậu. Tổ tuần tra đã ra tín hiệu dừng phương tiện để kiểm tra, xử lý. Làm việc với tổ công tác, người vi phạm đã thừa nhận những lỗi mà mình mắc phải và moong muốn được lực lượng công an xem xét giảm bớt mức xử phạt. Lúc này, Trần Đình Sang điều khiển ô tô đến vị trí xử lý vi phạm, sử dụng điện thoại quay phim, phát trực tiếp trên $\mathrm{MXH}$, đồng thời liên tục có những lời lẽ xúc phạm, khiêu khích đối với cán bộ chiến sĩ trong tổ công tác.

Trước thông tin Trần Đình Sang bị bắt, các đối tượng vội vàng đưa lên trên $\mathrm{MXH}$ rằng vô cớ bị bắt. Thậm chí, chúng còn xuyên tạc rằng Trần Đình Sang bị bắt vì công an muốn bịt miệng người dân đấu tranh với nạn mãi lộ và những sai phạm của cảnh sát giao thông [10].

\section{GIẢI PHÁP HẠN CHẾ TÁC HẠI CỦA CÁC THÔNG TIN XẤU, ĐỘC TRÊN MXH ĐỐI VỚI HỌC SINH, SINH VIÊN TRONG GIAI ĐOẠN HIỆN NAY}

Trước những thông tin xấu, độc trên $\mathrm{MXH}$ như hiện nay, cần quan tâm thực hiện các giải pháp để hạn chế mặt tiêu cực của $\mathrm{MXH}$, từ đó phát huy mặt tích cực để phục vụ học tập, nghiên cứu, vui chơi giải trí của học sinh, sinh viên. Sau đây tác giả đề xuất một số giải pháp cụ thể như sau:

Một là, đối với bản thân học sinh, sinh viên cần phải xác định mục tiêu đúng đắn khi tiếp cận $\mathrm{MXH}$. Phải chắc chắn rằng hành động này nhằm mang lại sự hiểu biết tri thức, hỗ trợ tích cực cho việc học tập, làm việc và vui chơi một cách tích cực. Luôn chủ động nâng cao kiến thức xã hội về mọi mặt nhằm xây dựng cho mình nhận thức chính trị đúng đắn để xem xét, tiếp cận thông tin một cách khách quan, đầy đủ, chính xác từ những nguồn thông tin chính thống, tránh tiếp cận thông tin phiển diện, một chiều. Nâng cao tinh thần cảnh giác, sã̃n sàng tham gia đấu tranh với những nhận thức không đúng, ngộ nhận, mơ hồ trước các nguồn thông tin sai trái, thù địch với quan điểm, đường lối của Đảng, chính sách và pháp luật của Nhà nước. Học sinh, sinh viên phải có ý thức tự giác, kỷ luật trong quá trình tiếp xúc thông tin; chấp hành tốt các quy định về quyền thông tin, phạm vi thông tin của công dân theo quy định của Hiến pháp năm 2013, Luật Tiếp cận thông tin năm 2016 và Luật An ninh mạng vừa mới được Quốc hội thông qua. Đồng thời tích cực tham gia vạch trần, cảnh báo đến người dùng $\mathrm{MXH}$ những biểu hiện xào xáo thông tin, lưu truyền thông tin xấu, độc, thông tin thất thiệt... Không nghe, đọc, xem những đài, báo, trang mạng, bài viết, blog, video của những phần tử chống đối, phản động. Không tán phát, chia sẻ thông tin kích động biểu tình hay hình ảnh, video, clip về cảnh tụ tập đông người, biểu tình gây rối. Không tin, nghe, làm theo hay ủng hộ lời xúi giục của kẻ xấu có những hành động vi phạm pháp luật (gây mất an ninh trật tự, vi phạm an toàn giao thông, gây thương tích cho người khác, chống người thi hành công vụ, hủy hoại tài sản của Nhà nước và doanh nghiệp...). Phát hiện, tố giác và sẵn sàng tham gia đấu tranh ngăn chặn kẻ xấu kích động việc thực hiện hành vi vi phạm pháp luật, kịp thời thông báo cho các cơ quan, đoàn thể để xử lý. Tích cực chia sẻ những thông tin chính thống để cùng tuyên truyền vận động bạn bè, người thân, cộng đồng hiểu và nghiêm chỉnh chấp hành pháp luật, tin tưởng vào sự lãnh đạo của Đảng, Nhà nước, cấp ủy, chính quyền các cấp.

Hai là, đối với nhà trường cần tăng cường giáo dục nâng cao nhận thức, trách nhiệm, bản lĩnh chính trị cho học sinh, sinh viên. Chú trọng giáo dục Chủ nghĩa Mác - Lênin, tư tưởng Hồ Chí Minh, đường lối của Đảng, chính sách và pháp luật của Nhà nước, làm rõ âm mưu, thủ đoạn mới của các thế lực thù địch, của các đối tượng xấu trên MXH. Đề cập những vấn đề, sự kiện mà chúng lợi dụng xuyên tạc, mức độ nguy hại, ảnh hưởng của các thông tin xấu, độc. Phổ biến các quy định của pháp luật đến học sinh, sinh viên về tội đưa hoặc sử dụng trái phép thông tin mạng máy tính, mạng viễn thông tại Điều 288 của Bộ luật Hình sự 2015; Nghị định số 72/2013/NĐ-CP ngày 15/7/2013 của Chính phủ và Thông tư số 09/2014/BTTTT ngày 19/8/2014 của Bộ Thông tin và Truyền thông về hoạt động quản lý, cung cấp, sử dụng thông tin trên trang thông tin điện tử và $\mathrm{MXH}$, những hành vi bị nghiêm cấm trong sử dụng $\mathrm{MXH}$.

Tăng cường quản lý, nắm bắt kịp thời tình hình tư tưởng của học sinh, sinh viên, không để xảy ra hiện tượng học sinh, sinh viên bị kẻ địch móc nối, lôi kéo. Cần sâu sát, nắm vững mọi hoạt động và tình hình tư tưởng học sinh, sinh viên nhất là khi những luồng quan điểm thù địch, chống đối "mới” xuất hiện, những biểu hiện lệch chuẩn trong nhận thức chính trị. Đồng thời nhà trường phải có trách nhiệm trong quản lý thông tin có liên quan tới học sinh, sinh viên trên $\mathrm{MXH}$. Yêu cầu học sinh, sinh viên lên tiếng khi tài khoản cá nhân (Facebook, Zalo...) bị hack hoặc bị giả mạo, để tránh bị lừa đảo, chiếm đoạt tài sản, bôi nhọ, vu khống, hoặc bị lợi dụng phát tán thông tin xâu, độc cho người thân, bạn bè và cộng đồng mạng.

Ba là, đối với các tổ chức đoàn thể, tổ chức chính trị xã hội giúp học sinh, sinh viên nhận diện, tự phòng chống các thủ đoạn, nội dung thông tin xấu, độc trên $\mathrm{MXH}$. Chủ động, kịp thời cung cấp thông tin chính 
thống một cách đầy đủ, toàn diện. Chỉ rõ những thủ đoạn, tính chất nguy hại của thông tin xấu độc đối với xã hội; trang bị kiến thức cần thiết để mỗi người có thể tự sàng lọc, tiếp nhận thông tin hữu ích, chính thống, đồng thời “miễn dịch" với những thông tin xấu, độc làm nhiễu loạn môi trường xã hội.

Tuyên truyền mỗi học sinh, sinh viên tham gia MXH phải có kiến thức an ninh mạng cơ bản, biết nhận diện những trang thông tin, những diễn đàn trên $\mathrm{MXH}$ hay đăng tải những thông tin xấu độc, cảnh giác, thận trọng, sàng lọc, tiếp nhận thông tin hữu ích, chính thống, đồng thời có khả năng "miễn dịch" với những thông tin xấu, độc, có ý thức ngăn chặn, phản bác cái xấu một cách có lý, có tình, thuyết phục. Đối với những bài viết, video có nội dung xấu, độc được phát tán trên $\mathrm{MXH}$, học sinh, sinh viên cần lên tiếng phản bác hoặc hạn chế sự lan truyền của chúng bằng cách lựa chọn ẩn bài viết, báo Spam để quản trị mạng xử lý.

Bốn là, đối với cơ quan quản lý nhà nước về an ninh mạng phải xây dựng không gian mạng lành mạnh, không gây phương hại đến an ninh quốc gia, trật tự, an toàn xã hội, quyền và lợi ích hợp pháp của cơ quan, tổ chức, cá nhân được quy định tại Luật An ninh mạng. Xây dựng, đề xuất chiến lược, chủ trương, chính sách, kế hoạch và phương an bảo vệ an ninh mạng; phòng ngừa, đấu tranh với hoạt động sử dụng không gian mạng xâm phạm chủ quyền, lợi ích, an ninh quốc gia, trật tự, an toàn xã hội và phòng, chống tội phạm mạng; bảo đảm an ninh thông tin trên không gian mạng; xây dựng cơ chế xác thực thông tin đăng ký tài khoản số; cảnh báo, chia sẻ thông tin an ninh mạng, nguy cơ đe dọa an ninh mạng. Yêu cầu doanh nghiệp cung cấp dịch vụ trên mạng viễn thông, mạng Internet, các dịch vụ gia tăng trên không gian mạng, chủ quản hệ thống thông tin loại bỏ thông tin có nội dung vi phạm pháp luật về an ninh mạng trên dịch vụ, hệ thống thông tin do doanh nghiệp, có quan, tổ chức trực tiếp quản lý. Bển cạnh đó, có những cảnh báo để các đối tượng sử dụng $\mathrm{MXH}$ biết để nhận diện và phòng tránh các âm mưu của thế lực phản động, đặc biệt đối tượng là học sinh, sinh viên Việt Nam.

\section{KẾT LUÂN}

Có thể nói, MXH kết nối con người trên toàn thế giới, rút ngắn không gian, thời gian và thúc đẩy sự giao lưu hợp tác quốc tế. Những giá trị tích cực của MXH mang lại là không hề nhỏ đó là: (1) Là một trong những cách tốt nhất để giới thiệu bản thân đến tất cả mọi người, bày tỏ cảm xúc của bản thân, chia sẻ quan điểm cá nhân, gắn kết cộng đồng giúp thích nghi tốt hơn với sự thay đổi và vượt qua những áp lực và căng thẳng trong cuộc sống, tìm kiếm những cơ hội phát triển khả năng của mình, gặp gỡ và giao lưu với tất cả mọi người trên thế giới. Là kho thông tin phong phú giúp cho cá nhân dần cải thiện kỹ năng sống và trau dồi kiến thức và là kênh giải trí hữu hiệu. (2) MXH còn là một môi trường kinh doanh lí tưởng, đầy tiềm năng, giúp người sử dụng bán hàng online hay quảng cáo những sản phẩm của công ty, doanh nghiệp và tìm kiếm khách hàng tiềm năng.

Bên cạnh những giá trị tích cực thì MXH được ví như con dao hai lưỡi ẩn chứa nhiều vấn đề bất cập và hiểm họa khó lường đối với người sử dụng không đúng mục đích như sau: (1) Thông tin xấu độc tán phát trên MXH là những thông tin bịa đặt, bóp méo sự thật, xuyên tạc vấn đề, “đồi trắng, thay đen”, làm lẫn lộn đúng sai, thật giả; hoặc có một phần sự thật nhưng được đưa tin với dụng ý xấu, phân tích và định hướng dư luận bằng luận điệu sai trái, thù địch. Xuyên tạc sự thật lịch sử, phủ nhận Chủ nghĩa Mác - Lê-nin, tư tưởng Hồ Chí Minh, chống phá đường lối, chủ trương, chính sách của Đảng, Nhà nước, phủ nhận thành tựu của công cuộc đổi mới, bịa đặt, vu cáo, nói xấu các đồng chí lãnh đạo cấp cao của Đảng, Nhà nước, gây chia rẽ đoàn kết nội bộ, tìm mọi cách thúc đẩy "tự diễn biến", "tự chuyển hóa" nội bộ ta trên mọi lĩnh vực.... (2) Một số thông tin chưa được kiểm chứng, thông tin sai sự thật gây ảnh hưởng đển cá nhân, tổ chức; (3) Một số thông tin có những ngôn từ thô tục nội dung phản cảm, thậm chí soi mói, bình phẩm chủ quan chuyện đời tư của người khác, xúc phạm danh dự, nhân phẩm của nhiều cá nhân, gây bức xúc trong dư luận xã hội; vi phạm chuẩn mực đạo đức, văn hóa, thuần phong mỹ tục; kích động đồi trụy, bạo lực, bôi nhọ đời tư, vu khống...; (4) Khá nhiều người lựa chọn $\mathrm{MXH}$ là nơi để bày tỏ quan điểm của cá nhân mình về người khác, nói xẩu, công kích, miệt thị, người khác, thậm chí đưa thông tin sai lệch để vùi dập. Thông tin sai trái, độc hại có tính chất tội phạm như: Lừa đảo trên mạng, đánh cắp thông tin, mật khẩu, tán phát vi-rút... Trước những ưu điểm và hạn chế của $\mathrm{MXH}$, học sinh, sinh viên trong giai đoạn hiện nay cần chủ động trong việc nhận diện và phòng tránh những thông tin xấu độc trên $\mathrm{MXH}$ để từ đó phát huy những mặt tích cực trong học tập, nghiên cứu và nhu cầu giải trí của bản thân. Chủ động trước những hạn chế của MXH để tránh được sự lợi dụng của các lực lượng phản động trong thời kỳ bùng nổ công nghệ số. 


\section{TÀI LIỆU THAM KHẢO}

[1] Báo cáo thống kê các mạng xã hội của tổ chức, DN trong nước được cấp giấy phép và đang hoạt động năm 2018 của Viện Chiến lược Thông tin và Truyền thông (Bộ TT\&TT);

[2] Thống kê tất cả các mạng xã hội hiện nay (https://socialmedialist.org);

[3] Số liệu thống kê về các trang mạng phổ biến nhất trên thế giới được xếp hạng theo số lượng tài khoản đang hoạt động (https://www.statista.com);

[4] Số liệu thống kê internet Việt Nam năm 2018 (https://www.dammio.com);

[5] Số liệu thống kê dân số Việt Nam (https://danso.org/viet-nam/);

[6] Nguyễn Thị Lan Hương, Thực trạng sử dụng MXH của thanh thiếu niên ở Việt Nam hiện nay (http://vanhien.vn);

[7] Đặng Thị Diệu Trang, Ngôn ngữ teen trong giao tiếp của giới trẻ hiện nay (vanhoahoc.vn);

[8] Vạch mặt những kẻ đứng sau kính động giáo dân gây rối ở Nghệ An, Hà Tĩnh (https://vtc.vn/)

[9] Khởi tố phóng viên Lê Duy Phong (https://tuoitre.vn);

[10] Công an Yên bái bắt một facebooker gây rối cảnh sát giao thông (https://tuoitre.vn);

[11] Ngăn chặn đẩy lùi tiêu tực từ mạng xã hội đối với thanh niên Quận đội trong giai đoạn hiện nay (http://hocvienpkkq.com);

[12] Cảnh giác trước thông tin xấu, độc trên mạng Internet (http://anninhthudo.vn);

[13] Lừa tiền trên mạng xã hội: Vì sao nhiều người mắc bẫy? (http://antg.cand.com.vn);

[14] Tổng thống Pháp tuyên chiến với thông tin giả mạo trên Internet (https://tuoitre.vn);

[15] Gần 36 triệu người Việt dùng di động truy cập mạng xã hội hàng ngày (http://viettimes.vn);

[16] Nguyễn Nhâm, Phòng chống thông tin xấu độc trên mạng xã hội (http://lyluanchinhtri.vn);

[17] Bộ Luật Hình sự năm 2015, Điều 288 (Tội đưa hoặc sử dụng trái phép thông tin mạng máy tính, mạng viễn thông);

[18] Luật An ninh mạng năm 2018, Điều 8 (Các hành vi bị nghiêm cấm về an ninh mạng);

[19] Nghị định số 72/2013/NĐ-CP ngày 15/7/2013 của Chính phủ về quản lý, cung cấp, sử dụng dịch vụ Internet và thông tin trên mạng;

[20] Thông tư số 09/2014/BTTTT ngày 19/8/2014 của Bộ Thông tin và Truyền thông quy định chi tiết về hoạt động quản lý, cung cấp, sử dụng thông tin trên trang thông tin điện tử và mạng xã hội.

Ngày nhận bài: 12/09/2019

Ngày chấp nhận đăng: 07/02/2020 